
ного Тагискена. Поздний бронзовый век Нижней Сырдарьи. М.: Восточная литература РАН, 2001. 295 с.

25. Хлопин И.Н. Юго-Западная Туркмения в эпоху поздней бронзы. По материалам Сумбарских могиль-

ников. Л.: Наука, 1983. 242 с.

26. Матющенко В.И. Еловский археологический комплекс. Часть вторая. Еловский II могильник. Доирменские комплексы. Омск: Изд-во ОмГУ, 2004. 468 с.

(C) 2015

\title{
IMPORTED CERAMICS FROM THE SETTLEMENT KENT
}

V.G. Loman, candidate of history sciences, director of the Saryarka Archaeological Institute E.A. Buketov Karaganda State University, Karaganda (Kazakhstan)

Abstract. At the end of the Bronze Age so-called community of the roll ceramics cultures (CRCC) occupied the territory of the steppe belt of Eurasia. Despite the vast distances that separate sites, ceramic vessels of these cultures have a high degree of resemblance. The technical and technological analysis of pottery enables, in particular, to determine the depth of the cultural differences of the ancient population groups. Unfortunately, such analysis for most cultures of the CRCC not carried out, and this fact greatly complicates the work to establish the degree of kinship and identification of contacts existed between them. This article analyzes the ceramic assemblage of Kent settlement - the largest for Sargary-Alekseev culture, part of CRCC. It was found that the population that left the site, consisted of not less than 3-4 groups, which were in the process of mixing. On the base of comparison of the results of technical and technological analysis it was found the pottery, imported from related communities. In addition, the technology of foreign culture pottery samples is considered and conclusions about areas of their origin are made. Vessels with ornaments and shape similar to the synchronous archaeological cultures of Western Siberia and Central Asia are attributed as foreign. It was found that ceramics, coming from Central Asia, was constructed by sculptural modeling methods, and a potter's wheel was used only for profiling the main part of the container. It is concluded that Sargary-Alekseev groups were not closed communities. They were in constant contact with related settlements and also in trade and exchange relations with the population of neighboring areas.

Keywords: the Bronze Age; Sargary-Alekseev culture; Dandybay pottery; wheel-made ceramics; pottery technology; technical and technological analysis

УДК 902.2

\section{ТЕХНИКО-ТЕХНОЛОГИЧЕСКИЙ АНАЛИЗ КЕРАМИКИ ИЗ МОГИЛЬНИКА СТАРО-ЯППАРОВО-1}

(C) 2015

В.И. Мухаметдинов, инженер учебно-научной археологической лаборатории Башкирский государственный университет, Уфа (Россия)

$\boldsymbol{A} . \boldsymbol{K}$ Б Бахшиева, хранитель фондов учебно-научного археологического музея Башкирский государственный университет, Уфа (Россия)

Аннотация. Статья посвящена проблеме срубно-алакульских контактов. В ней представлены результаты технико-технологического анализа керамики из курганного могильника Старо-Яппарово-1, расположенного в Республике Башкортостан. Были получены данные об отборе и обработке исходного сырья, составлении рецептов формовочных масс, способе конструирования начинов и полых тел, орнаментации и термической обработке. Было отмечено, что способы изготовления сосудов, зафиксированные по керамике со СтароЯппаровского могильника, были массово распространены на развитом этапе существования срубной КИО. Эти данные могут скорректировать первоначальные представления о хронологической позиции памятника, полученные по результатам исследования погребального обряда. Анализ позволил выделить как срубные, так и алакульские гончарные традиции, что свидетельствует о культурных контактах. Был сделан вывод, что население, оставившее курганный могильник Старо-Яппарово-1 было неоднородным, но относящееся при этом, в основном, к срубной историко-культурной общности.

Отсутствие в формовочных массах сосудов с памятника тальковой дресвы - надежного индикатора алакульского гончарства в Зауралье, а также отсутствие ее в составе шамота, позволяет сказать, что влияние алакульских племен на данной территории было не прямым, а опосредованным, через контактную зону в степном Приуралье.

Ключевые слова: Южный Урал; поздняя бронза; гончарные традиции; культурные контакты; алакульская культурно-историческая общность; срубная культурно-историческая общность.

Одной из наиболее актуальных проблем в изучении позднего бронзового века Южного Урала остается проблема срубно-алакульских контактов. Особенно пристальное внимание при ее разработке оказывается вопросам времени начала межкультурного взаимодействия, направления движения культурных групп 
и характеру связей.

Традиционно в раскрытии поставленных вопросов ключевую роль играет анализ керамической посуды, являющейся чутким индикатором происходивших в традиционных обществах этнокультурных процессов. Основные характеристики керамики, использующиеся исследователями в анализе, - форма сосудов, их орнаментация и визуально определимые технологические приемы их изготовления $[1 ; 2 ; 3 ; 4 ; 5 ; 6 ; 7]$. В то же время исследователями признается необходимость применения специальных методов анализа керамики, позволяющих определить происхождение технологических традиций, использовавшихся мастером при изготовлении каждого конкретного сосуда. Подобный подход может помочь в раскрытии механизмов межкультурных взаимодействий.

В рамках исследования гончарных технологических традиций на памятниках Южного Урала, материалы которых отражают связи срубного и алакульского населения, авторами данной работы был проведен технико-технологический анализ керамики с курганного могильника Старо-Яппарово-1, открытого в 1963 возле д. Старо-Яппарово Давлекановского района БАССР в ходе разведочных работ под руководством Г.И. Матвеевой. В 1973 году экспедицией Башкирского государственного университета было исследовано 4 кургана. Авторы раскопок датируют могильник третьей четвертью II тыс. до н.э., относя его к покровскому этапу срубной культуры [8].

Материалы Старо-Яппаровского могильника, наряду с материалами других южноуральских памятников эпохи поздней бронзы, были использованы Н.Г. Рутто в обобщающей работе «Срубно-алакульские связи на Южном Урале» для анализа взаимодействий срубного и алакульского населения. Исследователь делает вывод, что срубно-алакульские погребения на памятнике составляют 78,57\% (11 погребений из 14). Основанием для выделения срубно-алакульских погребений на могильнике служит, в основном, наличие в них сосудов синкретичного облика. Синкретичность же проявляется преимущественно в использовании алакульских орнаментальных мотивов и техники нанесения орнаментов в декорировании срубных, по форме, сосудов [3, С. 65].

Из 19 сосудов, найденных на могильнике, доступными для технологического анализа оказались 15: 1 сосуд из кургана №1, 6 из кургана №2, 2 из кургана №3 и 6 из кургана №4. Указанные сосуды были проанализированы по методике А.А. Бобринского в рамках разработанного им историко-культурного подхода [9; 10]. Гончарная технология, в рамках данного подхода, рассматривается как системное образование, состоящее из уровней - стадий керамического производства (подготовительная, созидательная и закрепительная), разделенных на десять ступеней - обязательных задач, выполнение которых необходимо для изготовления сосуда. В рамках подготовительной стадии - это 1) отбор, 2) добыча и 3) обработка исходного сырья, 4) составление формовочной массы; созидательной стадии - 5) конструирование начина и 6) полого тела
ТЕХНИКО-ТЕХНОЛОГИЧЕСКИЙ АНАЛИЗ КЕРАМИКИ... сосуда, 7) придание ему формы и 8) механическая обработка его поверхностей; закрепительной стадии - 9) придание сосуду прочности и 10) устранение влагопроницаемости его стенок. Кроме того, существуют две необязательные ступени в рамках созидательной стадии: 11) создание рельефных частей сосуда и 12) орнаментация сосуда. В текстовой части работы будет представлена общая информация о гончарных традициях, зафиксированных на памятнике, после чего, в таблицах - данные по каждому отдельному сосуду.

\section{1. Подготовительная стадия}

В качестве исходного пластичного сырья при изготовлении сосудов из Старо-Яппаровского-1 курганного могильника использовалась ожелезненная глина двух видов. Первый вид - среднепластичная глина с естественным содержанием мелкого песка (до 0,5 мм) в концентрации 1:5 - 1:6. Второй вид - высокопластичная глина, либо не содержал естественной примеси песка, или содержал его в незначительной концентрации (до 1:7). Из среднепластичной глины изготовлено 10 сосудов, а из высокопластичной - 5 сосудов. Глина использовалась в естественно-увлажненном состоянии. Только в одном случае, сосуд из погребения 2 кургана 4 был изготовлен из глины, замешанной в сухом дробленом состоянии.

Из непластичного исходного сырья в керамике памятника были зафиксированы шамот, песок и органические примеси. Шамот представлен включениями дробленых фрагментов сосудов размером от 0,1 мм (шамотная пыль) до 5 мм. Наиболее часто встречающаяся размерность шамота - 1-3 мм. Концентрация шамота варьируется от 1:4 до 1:7, без превалирования какого-либо из ее значений.

Вероятно, присутствующий в формовочной массе сосуда 2 погребения 1 кургана 2 цветной окатанный песок размером 0,5-1 мм (единичные песчинки 2-3 мм) был добавлен искусственно. Об этом, кроме относительно крупного размера песчинок, может свидетельствовать и большая его концентрация - 1:4 (5).

Органические примеси представлены навозом травоядных животных и органическими растворами. Органический раствор характеризуется аморфными полостями размером до 2 мм, на стенках которых фиксируются черный глянцевый, бурый, рыжий или белесый налеты, в ряде случаев встречаются отпечатки измельченной растительности, размером не превышающие 2 мм. Вид органического раствора определить сложно. Отдельные признаки (аморфные поры, отпечатки растительности, белесый налет) можно связать с выжимкой из навоза [11]. Но происхождение углистого глянцевого налета и бурого налета определить не удалось.

Основной рецепт формовочных масс на памятнике - глина + шамот + органический раствор (7 случаев). При этом он встречается исключительно в курганах №3 и №4. Рецепт с шамотом и навозом (3 случая) дважды встречается в кургане №2 и единожды в кургане №4. Смешанный рецепт - глина + шамот + навоз + орг. раствор (4 случая) фиксируется в единственном сосуде из кургана №1. Остальные 3 случая представ- 

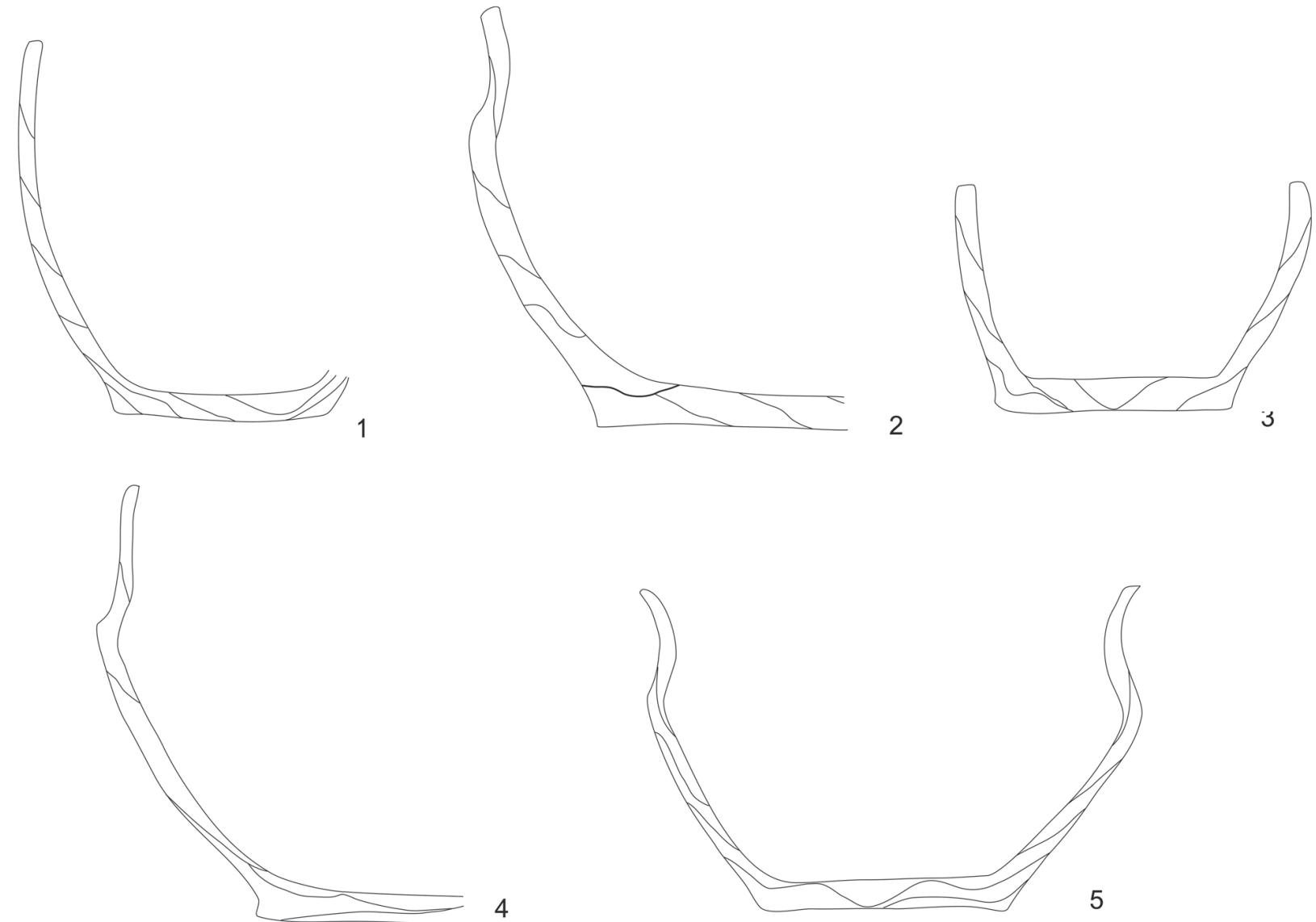

4

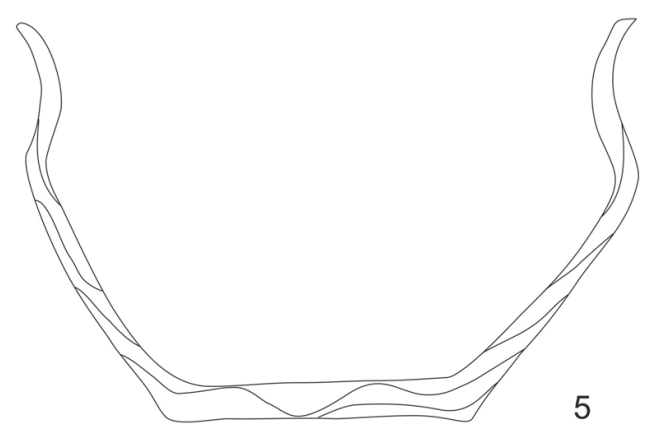

Рисунок 1 - Спаи между конструктивными элементами в изломах сосудов из Старо-Яппаровского-1 курганного могильника.

1 - курган 4, погребение 1, сосуд 1, донно-емкостный спирально-жгутовой начин, лепка на плоскости; 2 - курган 4, погребение 2, донный спирально-жгутовой начин, лепка на плоскости; 3 - курган 4, погребение 1, сосуд 3, донноемкостный, спирально жгутовой начин, форма-емкость; 4 - курган 2, погребение 4, донно-емкостный спиральнолоскутный начин, форма-основа; 5 - курган 4, погребение 4, донно-емкостный спирально-лоскутный начин, лепка на плоскости.

лены только в кургане №2. Там же зафиксирован еще один смешанный рецепт - глина + шамот + песок + навоз + органический раствор.

\section{2. Созидательная стадия}

Из 15 изученных сосудов только у 12 удалось определить способ конструирования начина. За исключением одного донного начина (сосуд К4П2, рис. 1: 2), все начины были изготовлены по донноемкостной программе. В качестве элементов конструирования использовались как жгуты, навитые по спирали (7 случаев), так и лоскуты, наложенные также по спирали (5 случаев). Закономерности в распределении начинов по курганам нет (таблица №1). Способ наложения элементов конструирования и их вид у полых тел проанализированных сосудов совпадал со способом наложения и видом элементов, из которых изготавливались их начины.

Большинство сосудов были изготовлены путем скульптурной лепки на плоскости. Два сосуда могли быть сделаны на форме основе (К2П3 и К2П4 (рис. 1: 4)), о чем говорит сильная деформация элементов конструирования в сочетании с лоскутной программой. Одна банка, вероятно, была сделана в форме емкости (К4П1С3, рис. 1: 3), поскольку на ее внешней поверх- ности местами фиксируются статичные отпечатки ткани тонкого плетения.

Из способов обработки поверхности сосудов были выделены заглаживание и лощение. Финишное заглаживание производилось, в основном, мягкими предметами: тканью (4 случая), кожей (2 случая) или овчиной (1 случай). В двух случаях при этом удалось зафиксировать следы первоначального, более грубого заглаживания щепой и деревянным ножом. Два сосуда были заглажены гладким твердым предметом, один - деревянным ножом. Залощены были пять сосудов. Четыре из них лощились по подсушенной поверхности, а один по поверхности в кожетвердом состоянии.

Орнамент на сосуды наносился различными способами. Зафиксированы оттиски гладкого штампа (4 случая), среднегребенчатого штампа (3 случая), ребристого штампа (1 случай) и шнура (1 случай).

\section{3. Закрепительная стадия}

Обжиг всех сосудов был костровым либо очажным. В шести случаях при обжиге сосуды изолировались от воздуха, с целью получить равномерно серый цвет поверхности. У сосудов, обжигавшихся в окислительной среде (9 случаев) притом, что поверхность была окрашена в цвета теплых оттенков, изломы, в 
основном, были одноцветно черными. Следовательно, температура каления воздействовала на сосуды очень непродолжительное время. Поверхность трех сосудов из кургана №4 после обжига была обварена.

\section{Выводы}

Практически все выделенные на памятнике гончарные традиции характерны для срубных племен, что подтверждается анализом керамических коллекций с памятников Среднего Поволжья и степного Приуралья [12]. Кроме того, обращает на себя внимание, что способы изготовления сосудов, зафиксированные по керамике со Старо-Яппаровского могильника, массово распространены в развитом периоде существования срубной КИО. В то время как такие характерные для раннего этапа традиции, как использование глиноподобного сырья (илов, илистых глин), примеси дробленой раковины [13] на изученных сосудах - не встречены. Ранним признаком можно назвать только единожды встреченный способ орнаментации оттисками шнура. Следовательно, данные анализа указывают на возможность корректировки хронологической позиции памятника, отмеченной, в том числе, и в обобщающей работе М.Ф. Обыденнова и Г.Т. Обыденновой [14, с. 135].

Стоит в то же время отметить, что некоторые из выделенных гончарных традиций характерны также и для алакульских племен. В первую очередь это конструирование начинов сосудов по донно-емкостной программе из лоскутов, с использованием форм-основ [15]. В то же время, можно заметить, что сосуды, изготовленные по лоскутной программе, в основном, не обладают внешними алакульскими признаками. Подобная ситуация фиксируется в гончарных традициях населения, оставившего Боголюбовский курганный могильник в Западном Оренбуржье [16]. Другая традиция широко распространенная в алакульском гончарстве - лощение поверхности. Кроме того, такие способы получения равномерно серого или черного цвета поверхности, как обжиг в восстановительной среде и обваривание также больше распространены у алакульских племен, нежели у срубных [17].

Таким образом, можно сделать вывод, что население, оставившее курганный могильник Старо-Яппарово-1, было неоднородным, но относящееся при этом, в основном, к срубной историко-культурной общности. Широкое применение на памятнике слабо распространенных у срубных племен традиций лощения поверхности и обжига сосудов в восстановительной среде указывает на контакты с алакульским населением. Относится ли к алакульскому влиянию использование лоскутного налепа с применением форм-основ, на данный момент сложно, поскольку в редких случаях он использовался и «срубниками» [12, С. 143]. Также, в формовочных массах сосудов с памятника и в составе шамота отсутствует тальковая дресва - надежный индикатор алакульского гончарства в Зауралье. Данное обстоятельство позволяет согласиться с мнением о том, что влияние алакульских племен на данной территории было не прямым, а опосредованным, очерез контактную зону в степном Приуралье [18], где указанная примесь периодически встречается $[19 ; 20]$.

Таблица 1 - Технологические данные об исходном сырье, рецептах формовочных масс и конструировании отдельно по каждому сосуду.

\begin{tabular}{|c|c|c|c|c|c|c|c|c|c|c|c|c|c|c|c|}
\hline \multirow[t]{2}{*}{ № } & \multirow[t]{2}{*}{$\begin{array}{l}\text { местона- } \\
\text { хождение }\end{array}$} & \multicolumn{2}{|c|}{$\begin{array}{l}\text { исходное } \\
\text { сырье }\end{array}$} & \multicolumn{4}{|c|}{ рецепт формовочных масс } & \multicolumn{3}{|c|}{$\begin{array}{c}\text { конструирование } \\
\text { начина }\end{array}$} & \multicolumn{2}{|c|}{$\begin{array}{c}\text { конструирование } \\
\text { полого тела }\end{array}$} & \multicolumn{3}{|c|}{$\begin{array}{c}\text { формообразова- } \\
\text { ние }\end{array}$} \\
\hline & & $\Gamma 1$ & $\Gamma 2$ & $\begin{array}{l}\Gamma+\amalg \\
+\mathrm{OP}\end{array}$ & $\begin{array}{c}\Gamma+\amalg \\
+\mathrm{H}\end{array}$ & $\begin{array}{c}\Gamma+\amalg \\
+\mathrm{H}+\mathrm{OP}\end{array}$ & $\begin{array}{l}\Gamma+\amalg+\Pi \\
+\mathrm{H}+\mathrm{OP}\end{array}$ & $\begin{array}{l}\text { ДЕ, } \\
\text { СЖ }\end{array}$ & $\begin{array}{c}\text { Д, } \\
\text { СЖ }\end{array}$ & $\begin{array}{l}\text { ДЕ, } \\
\text { СЛ }\end{array}$ & СЖ & СЛ & ЛП & ФО & $\Phi \mathrm{E}$ \\
\hline 1 & К1П1 & & + & & & + & & & & & & & & & \\
\hline 2 & К2П1С1 & & + & & & + & & + & & & + & & + & & \\
\hline 3 & К2П1С2 & & + & & & & + & + & & & + & & + & & \\
\hline 4 & К2П2 & & + & & + & & & & & & & & & & \\
\hline 5 & К2П3 & & + & & & + & & & & + & & + & & + & \\
\hline 6 & К2П4 & + & & & & + & & & & + & & + & & + & \\
\hline 7 & К2П6 & & + & & + & & & & & & & + & & & \\
\hline 8 & К3П1 & & + & + & & & & + & & & + & & + & & \\
\hline 9 & К3П2 & & + & + & & & & . & & + & . & + & + & & \\
\hline 10 & К4П1С1 & + & & & + & & & + & & & + & & + & & \\
\hline 11 & К4П1С2 & + & & + & & & & + & & & + & & + & & \\
\hline 12 & К4П1С3 & & + & + & & & & + & & & + & & & & + \\
\hline 13 & К4П2 & & + & + & & & & & + & & + & & + & & \\
\hline 14 & К4П3 & + & & + & & & & & & + & & + & + & & \\
\hline 15 & К4П4 & + & & + & & & & & & + & & + & + & & \\
\hline
\end{tabular}

Примечание: Г1 - высокопластичная глина, Г2 - среднепластичная глина, Г - глина, Ш - шамот, П - песок, ОР - органический раствор, Н - навоз, ДЕ - донно-емкостный начин, Д - донный начин, СЖ - спирально-жгутовой налеп, СЛ - спирально-лоскутный налеп, ЛП - лепка на плоскости, ФО - форма-основа, ФЕ - форма емкость. 
В.И. Мухаметдинов, А.К. Бахшиева

ТЕХНИКО-ТЕХНОЛОГИЧЕСКИЙ АНАЛИЗ КЕРАМИКИ...

Таблица 2 - Технологические данные об обработке поверхности и термической обработке отдельно по каждому сосуду.

\begin{tabular}{|c|c|c|c|c|c|c|c|c|c|c|c|c|c|c|}
\hline \multirow[t]{2}{*}{ № } & \multirow[t]{2}{*}{$\begin{array}{l}\text { местона- } \\
\text { хождение }\end{array}$} & \multicolumn{7}{|c|}{ заглаживание } & \multicolumn{5}{|c|}{$\begin{array}{c}\text { термическая обработка } \\
\text { (среда/цвет излома) }\end{array}$} & \multirow[t]{2}{*}{ обвар } \\
\hline & & Л & Ов & $\mathrm{T}$ & K & Гл & ДН & Щ & О/1цв & $\mathrm{O} / 2$ цв & $\mathrm{O} / 3$ цв & В/1цв & В/3цв & \\
\hline 1 & К1П1 & & & & & + & & & & & & + & & \\
\hline 2 & К2П1С1 & & & & & & + & & & & + & & & \\
\hline 3 & К2П1С2 & & & & + & & & & & + & & & & \\
\hline 4 & К2П2 & & & & & + & & & & & & + & & \\
\hline 5 & К2П3 & & + & & & & + & & & & & + & & \\
\hline 6 & К2П4 & & & + & & & & & & & + & & & \\
\hline 7 & К2П6 & + & & & & & & & + & & & & & \\
\hline 8 & КЗЗП1 & + & & & & & & & + & & & & & \\
\hline 9 & К3П2 & + & & & & & + & & & & & + & & \\
\hline 10 & К4П1С1 & & & + & & & & + & & & & & + & \\
\hline 11 & К4П1С2 & & & & + & & & & + & & & & & \\
\hline 12 & К4П1С3 & + & & & & & & & & + & & & & \\
\hline 13 & К4П2 & & & + & & & & & & & & + & & + \\
\hline 14 & К4П3 & & & + & & & & + & & + & & & & + \\
\hline 15 & К4П4 & + & & & & & & & & & + & & & + \\
\hline
\end{tabular}

Примечание: Л - лощение, Ов-овчина, Т - ткань, К-кожа, Гл - галька, Щ - щепа, ДН - деревянный нож, О - окислительная среда, В - восстановительная среда.

Таблица 3 - Технологические данные о способах орнаментации отдельно по каждому сосуду.

\begin{tabular}{|c|c|c|c|c|c|c|}
\hline \multirow[t]{2}{*}{ № } & \multirow[t]{2}{*}{ местонахождение } & \multicolumn{5}{|c|}{ орнамент } \\
\hline & & нет & $\Gamma \mathrm{p}$ & $\mathrm{P}$ & Гл & Ш \\
\hline 1 & К1П1 & & + & & & \\
\hline 2 & К2П1С1 & & & & + & \\
\hline 3 & К2П1С2 & + & & & & \\
\hline 4 & К2П2 & + & & & & \\
\hline 5 & К2П3 & & & + & & \\
\hline 6 & К2П4 & & & & & + \\
\hline 7 & К2П6 & + & & & & \\
\hline 8 & К3П1 & & + & & & \\
\hline 9 & К3П2 & & & & + & \\
\hline 10 & К4П1С1 & & & & + & \\
\hline 11 & К4П1С2 & + & & & & \\
\hline 12 & К4П1С3 & + & & & & \\
\hline 13 & К4П2 & + & & & & \\
\hline 14 & К $4 \Pi 3$ & & + & & & \\
\hline 15 & К4П4 & & + & & & \\
\hline
\end{tabular}

Примечание: Гр -гребенчатый штамп, Р - ребристый штамп, , Гл - гладкий штамп, Ш - шнур.

\section{СПИСОК ЛИТЕРАТУРЫ:}

1. Сальников К.В. Очерки древней истории Южного Урала. М.: Наука, 1967. 408 с.

2. Морозов Ю.А., Нигматуллин Р.А. Этнокультурные связи срубных племен Приуралья в эпоху развитой бронзы (по материалам Петряевского могильника). Уфа: АН РФ АН РБ УНЦ, 1998. 40 с.

3. Рутто Н.Г. Срубно-алакульские связи на Южном Урале. Уфа: Гилем, 2003. 212 с.

4. Петрова Л.Ю. Керамические комплексы эпохи поздней бронзы степной зоны Южного Зауралья // Известия Челябинского научного центра. №2. Челябинск: 2007. С. 81-85.

5. Сунгатов Ф.А., Бахшиев И.И.Поселение эпохи поздней бронзы Олаир. Уфа: ГУП «Уфимский полиграфкомбинат», 2008. 200 с.

6. Алаева И.П.Специфика керамического комплексапозднего бронзового векастепной частиЮжного Зауралья // КСИА, Вып. 233. М.: Языки славянской культуры: Знак, 2014. С. 33-45. 
7. Бахшиев И.И. Срубно-алакульское взаимодействие на материалах могильника Тасты-Бутак 1 // Этносы и культуры Урало-Поволжья: история и современность: материалы VIII Всероссийской научно-практической конференции молодых ученых посвященной 85-летию со дня рождения Р.Г. Кузеева. Уфа: ИЭИ УНЦ РАН, 2014. С. 21-28.

8. Горбунов В.С., Обыденнов М.Ф. Курганы срубной культуры у деревни Старо-Яппарово на р. Деме // Известия Воронежского государственного педагогического института. Т. 198. Воронеж, 1978. С. 118-131.

9. Бобринский А.А. Гончарство Восточной Европы. Источники и методы изучения. М.: Наука, 1978. 272 с.

10. Бобринский А.А. Гончарная технология как объект историко-культурного изучения // Актуальные проблемы изучения древнего гончарства (коллективная монография). Самара: Изд-во СамГПУ, 1999. С. 5-109.

11. Илюшина В.В. Экспериментальные исследования органических растворов в археологической керамике // Экспериментальная археология. Взгляд в XXI век. Материалы международной полевой научной конференции «Экспериментальная археология. Взгляд в XXI в.». Ульяновск: Областная типография «Печатный двор», 2013. С. 40-45.

12. Васильева И.Н., Салугина Н.П. Некоторые итоги изучения древнего и средневекового гончарства // 40 лет средневолжской археологической экспедиции. Краеведческие записки. Вып. XV. Самара: ООО «Офорт», 2010. С. 135-154.

13. Салугина Н.П. Гончарство населения позднего бронзового века: к проблеме культурогенеза // Труды IV (XX) Всероссийского археологического съезда в Казани. Т. 1. Казань: Отечество, 2014. С. 643-646.
ТЕХНИКО-ТЕХНОЛОГИЧЕСКИЙ АНАЛИЗ КЕРАМИКИ..

14. Обыденнов М.Ф., Обыденнова Г.Т. Северо-восточная периферия срубной культурно-исторической общности. Самара: Изд-во Саратов.ун-та, Самарский филиал, 1992. 173 с.

15. Ломан В.Г. Андроновское гончарство: общие приемы изготовления сосудов // Культуры древних народов степной Евразии и феномен протогородской цивилизации Южного Урала. Челябинск: 1995. С. 97-100.

16. Моргунова Н.Л., Гольева А.А., Евгеньев А.А., Крюкова Е.А., Купцова Л.В., Рослякова Н.В., Салугина Н.П., Турецкий М.А., Хохлов А.А., Хохлова О.С.; под общ. Ред. Н.Л. Моргуновой Боголюбовский курганный могильник срубной культуры в Оренбургской области. Оренбург: Изд-во ОГПУ, 2014. 172 с.

17. Мухаметдинов В.И. Технологические традиции изготовления керамики на поселении Ново-Байрамгулово-1 // Вестник ВЭГУ №1 (69). Уфа: 2014. C. 218-228.

18. Алаева И.П. К вопросу о содержании и структуре срубно-алакульской контактной зоны в степях Южного Зауралья // Труды II (XVIII) Всероссийского археологического съезда в Суздале. Т. І. М.: ИА РАН, 2008. C. 375-377.

19. Купцова Л.В., Файзуллин И.А. Родниковое поселение позднего бронзового века в Западном Оренбуржье // Археологические памятники Оренбуржья. Вып. 10. Оренбург: Изд-во ОГПУ, 2012. С. 70-100.

20. Крюкова Е.А., Евгеньев А.А., Купцова Л.В., Матюшко И.В. Комплексы позднего бронзового века ПлешановскогоII курганного могильника // Археологические памятники Оренбуржья. Вып. 10. Оренбург: Изд-во ОГПУ, 2012. С. 112-134.

Исследование выполнено при финансовой поддержке РГНФ и Республики Башкортостан в рамках научного проекта 15-11-02006а(р) «Гончарные традиции населения Южного Приуралья в эпоху поздней бронзы. Проблемы культурных взаимодействий».

(C) 2015

\title{
TECHNICAL-TECHNOLOGICAL ANALYSIS OF CERAMICS FROM THE BARROW CEMETERY STARO-YAPPAROVO-1
}

\author{
V.I. Mukhametdinov, engineer of archaeological laboratory \\ Bashkir state university, Ufa (Russia) \\ A.K. Bahshieva, keeper of funds of archaeological museum. \\ Bashkir state university, Ufa (Russia)
}

\begin{abstract}
The article is devoted to problems of Srubnaya-and-Alakul contacts in South Ural. It presents results of the technological analysis of ceramic complexfrom barrow cemetery Staro-Yapparovo-1 in Republic of Bashkortostan.Data were obtained on the selection and processing of raw materials, the preparation of recipes moulding compounds, the method of construction of bases and walls, ornamentation and heat treatment of vessels. It was noted that the methods of manufacturing of vessels registered in ceramics with anStaro-Japparovo-1 burial ground, were massively common in the developed stage of the existence of the srubnahistorical-culture community. These data can adjust the original idea about the chronological position of the burial site, taken from the results of the study of the burial rite. The analysiswas able toidentifyasSrubnayaandAlakulpotterytraditions. It's evidenceof cultural contacts.It was concluded that the population that left burial mounds of Staro-Japparovo-1 was heterogeneous, but related this mainly withsrubna historical and cultural community.In the absence of the moulding compounds of vessels from the burial site of the talc grit(it's a reliable indicator of Alakul pottery in the Transurals), as well as its absence in the composition of grog, lets say that the influence of the Alakul tribes in this territory was indirect, through the contact area in the steppe of the Preurals.

Keywords: South Urals; late Bronze Age; pottery traditions; cultural contacts; Srubnayacultural-and-historical community; Alakul cultural-and-historical community.
\end{abstract}

